\title{
Electric current and magnetic field geometry in flapping magnetotail current sheets
}

\author{
A. Runov ${ }^{1}$, V. A. Sergeev ${ }^{2}$, W. Baumjohann ${ }^{1}$, R. Nakamura ${ }^{1}$, S. Apatenkov ${ }^{2}$, Y. Asano ${ }^{1}$, M. Volwerk ${ }^{1,6}$, Z. Vörös ${ }^{1}$, \\ T. L. Zhang ${ }^{1}$, A. Petrukovich ${ }^{3}$, A. Balogh ${ }^{4}$, J.-A. Sauvaud ${ }^{5}$, B. Klecker ${ }^{6}$, and H. Rème ${ }^{5}$ \\ ${ }^{1}$ Space Research Institute, Austrian Academy of Sciences, A-8042, Graz, Austria \\ ${ }^{2}$ St. Petersburg University, Russia \\ ${ }^{3}$ Space Research Institute, Russian Academy of Sciences, Moscow, Russia \\ ${ }^{4}$ Imperial College, London, UK \\ ${ }^{5}$ CESR, Toulouse, France \\ ${ }^{6} \mathrm{MPE}$, Garching, Germany
}

Received: 10 December 2004 - Revised: 3 March 2005 - Accepted: 29 March 2005 - Published: 3 June 2005

\begin{abstract}
Using four-point magnetic field measurements by the Cluster spacecraft, we statistically analyze the magnetic field and electric current configurations during rapid crossings of the current sheet observed in July-October 2001 at geocentric distances of $19 R_{E}$. The database includes 78 crossings, specially selected to apply multi-point data analysis techniques to calculate vector derivatives. Observed bipolar variations of $j_{z}$, often with $\left|j_{z}\right|>j_{y}$, indicate that the electric currents follow kinks of the current sheet. The current density varies between $5-25 \mathrm{nA} / \mathrm{m}^{2}$. The half-thickness of the current sheet during flapping varies over a wide range, from 1 to 20 ion thermal gyroradii $\left(L_{c p}\right.$, calculated from average temperature and lobe magnetic field for each crossing). We found no relationship between the tilt angle of the current sheet normal and the half-thickness. In 68 cases the magnetic field curvature vector has a positive (earthward) $X$-component. Ten cases with a negative (tailward) curvature, associated with reconnection, were detected within $0<Y_{G S M}<7 R_{E}$. The minimum curvature radii vary mainly between 1 and $10 L_{c p}$, and the adiabaticity parameter $\kappa \leq 1$ for $73 \%$ of the events. The electric current density during flapping is often off-central, i.e. the main current density is shifted from the neutral sheet $\left(\left|B_{x}\right|<5 \mathrm{nT}\right)$ to the Northern or Southern Hemisphere. This is most likely a temporal effect related to the flapping. The analysis shows that the flapping motion of the current sheet is associated with kink-like waves on the sheet surface. The kink fronts, tilted in the $Y-Z$ plane, moved toward dawn in the morning half and toward dusk in the evening half of the magnetotail.
\end{abstract}

Keywords. Magnetospheric physics (Magnetotail; Plasma sheet)

Correspondence to: A. Runov

(andrei.runov@oeaw.ac.at)

\section{Introduction}

Speiser and Ness (1967) noticed that the magnetotail current sheet frequently moves in the north-south direction. This motion, which has been referred to as flapping (Lui et al., 1978), provides the possibility to probe the structure of the current sheet during multiple crossings (Sergeev et al., 1993) and deduce an electric current density within the sheet (Sergeev et al., 1998). The interpretation of measurements during flapping was sometimes based on suggestions that flapping is an up-down motion of the magnetic field, together with plasma (Sergeev et al., 1998) and that the current sheet is a planar structure, with current distribution described by a Harris (1962) function (Sanny et al., 1994). However, even single-spacecraft measurements show indications that the geometry of the magnetotail current sheet is more complex than a planar surface, and that the sheet may be corrugated (Lui et al., 1978; Nakagawa and Nishida, 1989).

Case studies of the magnetotail current sheet with the Cluster four spacecraft constellation show that short-term $\left(\sim 30 \mathrm{~s}-\right.$ several minutes), large-scale variations $\left(\delta B_{x} \sim 15\right.$ $30 \mathrm{nT}$ ) of the magnetic field, which are typical manifestations of flapping, are associated mainly with wave-like structures on the current sheet surface, propagating in the cross tail direction (Zhang et al., 2002; Runov et al., 2003b; Sergeev et al., 2003). Sergeev et al. (2004) have shown by multi-point timing analysis that near the flanks $\left(8<\left|Y_{G S M}\right|<15 R_{E}\right)$ the flapping waves propagate from the central sector of the magnetotail toward the flanks. Moreover, the distribution of the current density within such transients is often far from that in the Harris sheet (Runov et al., 2003b; Sergeev et al., 2003).

In this paper we provide a statistical survey of the current sheet geometry, magnetic field gradient, curvature, and current density distribution during rapid crossings of the sheet during the 2001 Cluster tail season. 


\section{Method}

Calculations based on the reciprocal vectors (Chanteur, 1998) allow one to estimate the magnetic field gradient, curl, and divergence using linear interpolation between the Cluster tetrahedron nodes. Another method, based on a leastsquares minimization (Harvey, 1998), yields consistent results (Chanteur and Harvey, 1998). Both methods are sensitive to geometrical factors of the tetrahedron, such as its elongation $E$ and planarity $P$. During the tail season (July to October) the Cluster tetrahedron is nearly regular with $E \leq 0.1$ and $P \leq 0.1$ (Chanteur and Harvey, 1998) which is well-suited for calculations of the vector derivatives (Robert et al., 1998a). Test calculations and applications of the curlometer for Cluster data are described by Dunlop et al. (2002). Calculation of curl and divergence of $\mathbf{B}$ in the magnetotail lobe gives the median value $0.58 \pm 0.23 \mathrm{nT} / 1000 \mathrm{~km}$ and $0.21 \pm 0.17 \mathrm{nT} / 1000 \mathrm{~km}$, respectively.

Gradient estimates can also be used to estimate the magnetic field curvature vector $\mathbf{C}=(\mathbf{b} \cdot \nabla) \mathbf{b}$, where $\mathbf{b}=\mathbf{B} / B$. The curvature radius is the reciprocal value of the curvature vector $R_{c}=1 / C$. The accuracy of $R_{c}$ estimation using four-point measurements in the magnetotail is discussed by Shen et al. (2003).

The local normal to the current sheet can be obtained by Minimum Variance Analysis (e.g., Sonnerup and Schneible, 1998), by four-point timing analysis (Harvey, 1998), or by using $\nabla B^{2}$ (Shen et al., 2003) or the $\mathbf{l} \times[\nabla \times \mathbf{B}]$ direction, where $\mathbf{I}$ is the magnetic field maximum variance eigenvector (this study).

Using the estimated magnetic field gradient $\nabla \mathbf{B}$ and assuming that rapid crossings of the magnetotail current sheet are due to a translational motion of the entire sheet with velocity $\mathbf{U}$,

$\frac{d \mathbf{B}}{d t}=\frac{\partial \mathbf{B}}{\partial t}+(\mathbf{U} \cdot \nabla) \mathbf{B}=0$,

where integration of $U_{n}$ (component of the translation velocity along the current sheet normal) yields the effective coordinate across the current sheet

$Z^{*}(t)=\int_{t_{1}}^{t_{2}} \frac{\partial B_{l}}{\partial t}\left[\nabla_{n} B_{l}\right]^{-1} d t$,

where $B_{l}$ is the main, maximum variance component of the magnetic field (close to $B_{x}$ in the near-midnight part of the magnetotail) and $\nabla_{n}$ is the gradient along the current sheet normal. The half-thickness of the current sheet $h$ may be estimated as the width of the $j\left(Z^{*}\right)$ profile at $j=0.5 \max (j)$, or using a fit to the Harris function.

To examine the accuracy of the estimations, a set of test calculations was performed with the simplest Harris-type current sheet (see Appendix) and with two shifted Harris distributions (to model a bifurcated sheet) passing over a virtual spacecraft tetrahedron. Cluster configurations during September 2001 (close to a regular tetrahedron), mid July and end of October (maximum deviation from a regular tetrahedron) were used for the model calculations. The numerical experiments show that the direction of the current is reconstructed with an error of less than $20^{\circ}$ without any dependence on the tetrahedron configuration, but the current density magnitude might be underestimated up to $30 \%$. The scale $h$ is also underestimated up to $\sim 15 \%$, depending on the tetrahedron configuration and the mutual orientation of tetrahedron and model current sheet. Non-regularity of the spacecraft tetrahedron produces also some asymmetry of the reconstructed current density profile with a displacement of the peak of up to $\pm 500 \mathrm{~km}$ from $Z^{*}=0$. In turn, the magnetic field curvature radius, being proportional to a reciprocal value of a magnetic field gradient, might be overestimated.

\section{Data}

During the 2001 tail season (from mid of July until the end of October) the Cluster quartet crossed the magnetotail plasma sheet in the configuration of a nearly regular tetrahedron with the maximal scale of 1700-2000 km (Baumjohann and Nakamura, 2005). The 1-s averaged magnetic field data from the Flux Gate Magnetometer (FGM Balogh et al., 2001) and the 2-spin (normal mode) and 1-spin (4s, burst mode) averaged data from the Cluster Ion Spectrometry experiment (CIS, Rème et al., 2001) are used for the statistical analysis presented below.

We use the following criteria to select rapid current sheet crossings. First, we selected the events with large and rapid variations of $\left|B_{x}\right|$ at the Cluster barycenter: $\delta\left|B_{x}\right|>15 \mathrm{nT}$ during time interval $30 \leq \tau \leq 300 \mathrm{~s}$. During the 2001 tail season, 198 such cases were found. From this large data base only "complete" crossings, during which all four spacecraft cross (or, at least touch) the neutral sheet region $\left(\left|B_{x}\right|<5 \mathrm{nT}\right)$, were selected for further analysis. Besides, by visual inspection we selected smooth crossings without significant short time scale fluctuations and with similar shapes of magnetograms at all four spacecraft. For final selection we calculate curl and divergence estimations using 1-s averaged FGM data. Since the main source of the magnetic field divergence is an error of linear interpolation of the field within the tetrahedron, we selected events with $|\nabla \cdot \mathbf{B}| /|\nabla \times \mathbf{B}|<0.30$ in more than $60 \%$ of samples during the crossing (see Appendix).

It should be noted that the database does not contain thin current sheets with a thickness less than the Cluster tetrahedron scale, like those presented by Nakamura et al. (2002).

To avoid LLBL and magnetosheath samples, only crossings within $-15<Y<15 R_{E}$ were used (no storm-time events in the near flank region are included into the database). No selection by plasma parameters was applied. The final database contains 78 rapid current sheet crossings.

\section{Event study}

To illustrate our selection criteria and further analysis, we start by presenting one event. Figure 1 shows Cluster observations for a 500-s long interval after $\sim 15: 25$ UT on 12 
August 2001 (see Volwerk et al. (2004) for a detailed description of this event). During this time Cluster was located in the morning sector at $[-17.3,-6.0,5.0] R_{E}$ (coordinates of the barycenter). The relative positions of the spacecraft are shown in the inserted box in Fig. 1. The Cluster barycenter crosses the neutral sheet twice: first from north to south, then in the opposite direction. The instances of neutral sheet crossings $\left(t_{01}, t_{02}\right)$ are marked by vertical dashed lines. Crossing durations are $\sim 100 \mathrm{~s}$. $B_{y}$ was small and varied in between -3 and $3 \mathrm{nT}$, and $B_{z}$ was positive and reached $10 \mathrm{nT}$ during the crossings. The proton velocity was small $(\leq 100 \mathrm{~km} / \mathrm{s})$ at the beginning of the first crossing and around zero during the second one, $\mathrm{C} 1$ and $\mathrm{C} 4$ spacecraft show approximately the same values. The proton density was unusually high $\left(1.6-1.9 \mathrm{~cm}^{-3}\right)$, and the proton temperature was 1.8 and $2.4 \mathrm{keV}$, for both crossings, respectively, which is lower than the typical value ( $\sim 5 \mathrm{keV}$, see Baumjohann et al., 1989). Thus, the Cold-Dense Plasma Sheet (CDPS), preceded by $\sim 7 \mathrm{~h}$ of positive IMF $B_{z}$ (ACE data, not shown) was observed.

The Z-component of the electric current density $\mathbf{j}=\mu_{0}^{-1} \nabla \times \mathbf{B}$ calculated from four-point magnetic field measurements was the largest component during both crossings, and showed a bipolar variation: $j_{z}>0$ during the first crossing and $j_{z}<0$ during the second one. This indicates a strong tilt of the current sheet in the $Y-Z$ plane. During the first crossing the current density maximum is seen before the neutral sheet crossing at barycenter $\left(t_{0}\right)$. The magnetic field curvature vector is directed earthward (positive curvature).

Visual inspection of the $B_{x}$ time series shows that a front of the flapping wave moves dawnward (-Y) so that the $\mathrm{C} 2$ spacecraft (red trace) crosses the neutral sheet first and $\mathrm{C} 4$ (blue) last. The order of magnetograms and time lags remain the same for both crossings: $\mathrm{C} 2 \rightarrow \mathrm{C} 3 \rightarrow \mathrm{C} 1 \rightarrow \mathrm{C} 4$ with delays (with respect to $\mathrm{C} 2$ ) of $44,20,13 \mathrm{~s}$ for the first crossing and $47,10,12 \mathrm{~s}$ for the second one. These timings yield a normal velocity of $25 \mathrm{~km} / \mathrm{s}$ with a normal direction $\mathbf{n}_{t 1}=[0.15$, $-0.99,0.04]$, and $28 \mathrm{~km} / \mathrm{s}$ and $\mathbf{n}_{t 2}=[0.16,-0.98,-0.12]$ for the first and second crossings, respectively. Results of a Minimum Variance Analysis (MVA) of the barycenter magnetic field time series are similar. For the first crossing the MVA yields $\mathbf{n}_{1}=[0.01,-0.99,0.15]$ with an eigenvalues ratio $\lambda_{2} / \lambda_{3}=8.57$. For the second crossing the minimum and intermediate variance directions are not well resolved $\left(\lambda_{2} / \lambda_{3}=2.17\right)$. We also computed the normals to the current density direction using the maximum variance components $\mathbf{l}_{1,2},\left(\lambda_{1} / \lambda_{2}=128\right.$.1: first crossing, $\lambda_{1} / \lambda_{2}=408.5$ : second crossing) and computing $\mathbf{n}_{j}=\mathbf{l} \times \mathbf{e}_{j}$, where $\mathbf{e}_{j}=\mathbf{j} / j$ is a unit vector along the current density direction, for both crossings. The results are $\mathbf{n}_{j_{1}}=[0.12,-0.86,0.46], \mathbf{n}_{j_{2}}=[0.05$, $-0.95,-0.22]$. This gives a consistency between timingand current-based normals: $\mathbf{n}_{t 1} \cdot \mathbf{n}_{j_{1}}=0.89$ and $\mathbf{n}_{t 2} \cdot \mathbf{n}_{j_{2}}=0.97$.

The results of this case study are summarized in Fig. 2. Panel a) shows a diagram inferred from the sheet orientations obtained: Cluster passes through a quasi-rectangular kink in the current sheet. The length of this kink (size in the $\mathrm{Y}$ direction) estimated from timing is $\sim 6000 \mathrm{~km}$. Panels

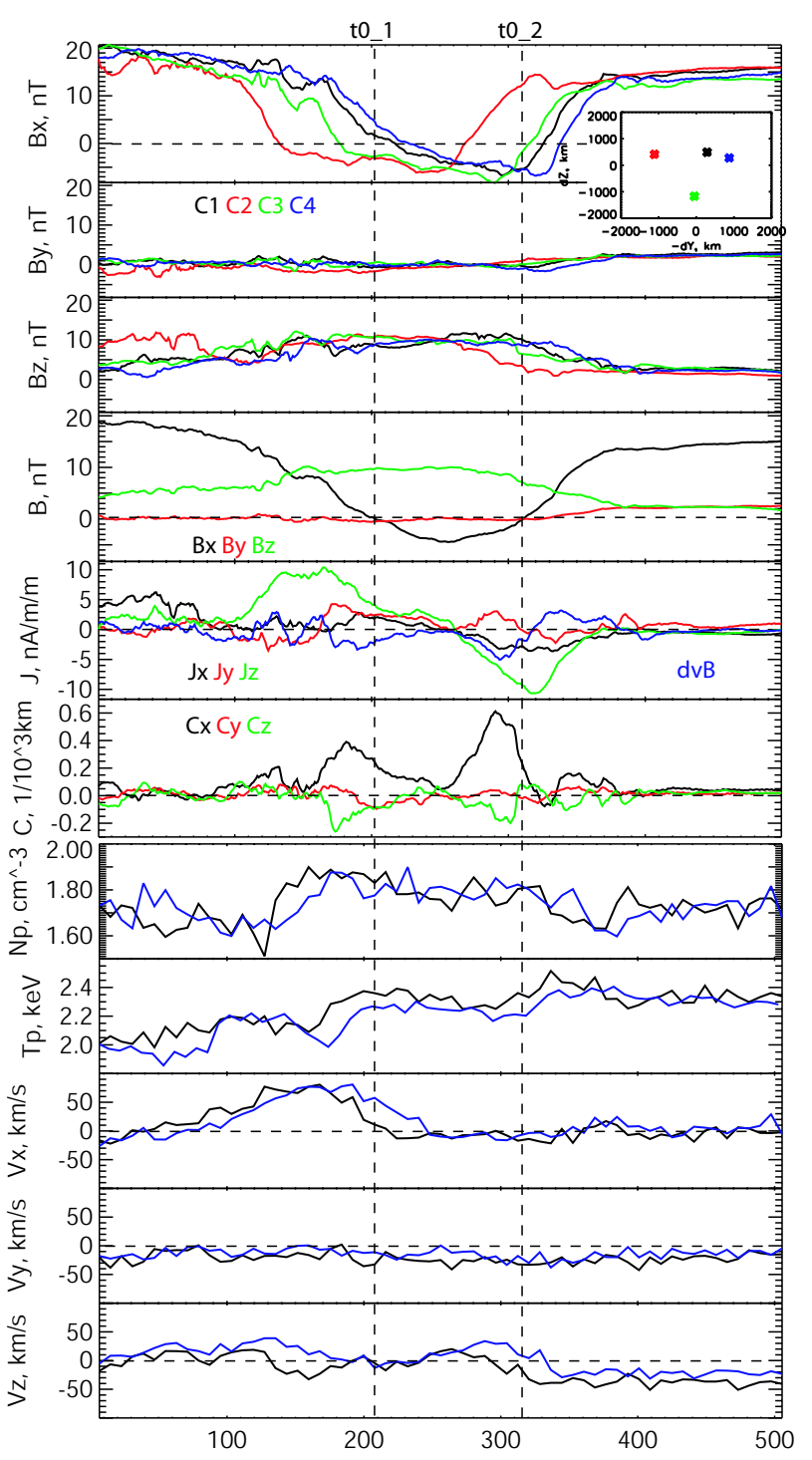

Fig. 1. $500 \mathrm{~s}$ of Cluster data from $\sim 15: 25$ UT, 12 August 2001. From top to bottom: $B_{x}, B_{y}, B_{z}$ from all four spacecraft; three components of $\mathbf{B}$ at the Cluster barycentre; three components of the calculated current density $\mathbf{j} ; \mathrm{X}-, \mathrm{Y}-$, and Z-components of the magnetic field curvature vector $\mathbf{C}=(\mathbf{b} \cdot \nabla) \mathbf{b} ; \mathrm{H}^{+}$density, pressure and bulk velocity (three components) from Cluster 1 and 4 .

b) and c) illustrate the vertical scale estimation made using Eq. (2) with the additional condition $Z^{*}\left(t_{0}\right)=0$. These calculations yield an amplitude of the kink of $6000 \mathrm{~km}$ which is equal to the kink length. It should be noted, however, that the accuracy of the amplitude estimate is rather poor for the structures with scales of the order of the inter-spacecraft separation scale (see Appendix). There were no current sheet crossings during $30 \mathrm{~min}$ before and $30 \mathrm{~min}$ after this kink (Volwerk et al., 2004), which implies that this structure could be a solitary wave. The kink velocity $V_{y} \sim 25 \mathrm{~km} / \mathrm{s}$ obtained from the timing is similar to the $Y$-component of the ion bulk velocity (see Fig. 1). Therefore, this kink may be transported with the ion flow. 


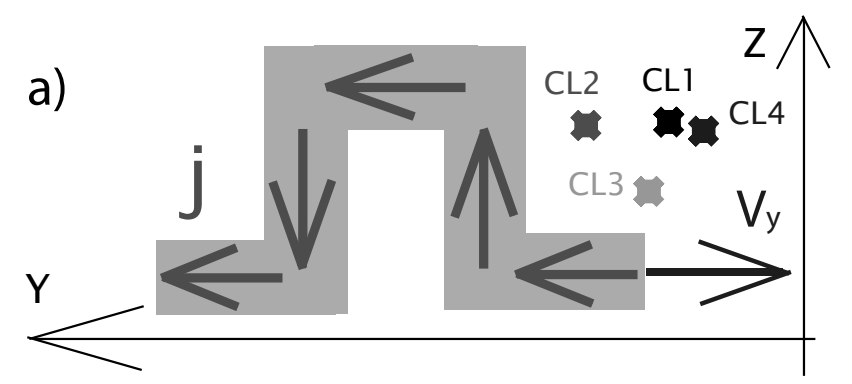

b)

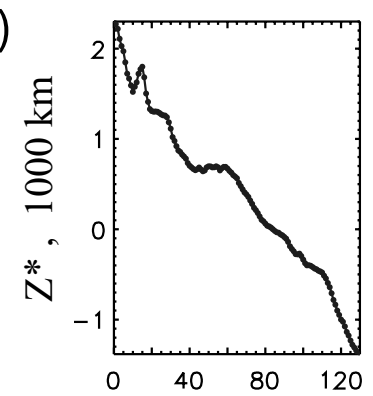

c)

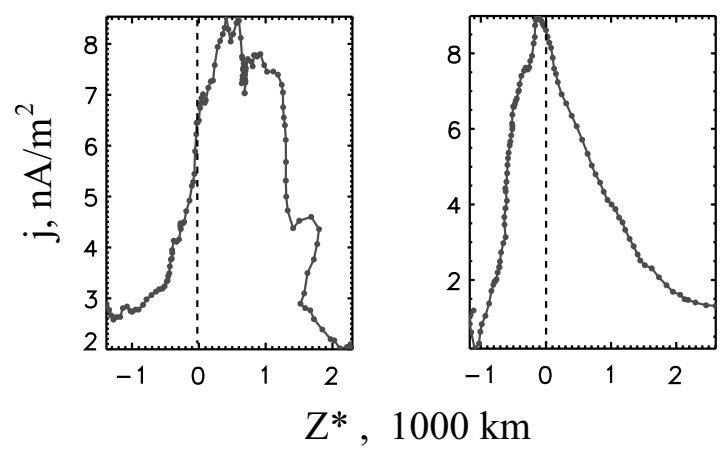

Fig. 2. (a) An interpretation of 12 August 2001 data: Sketch of the electric current geometry in the $Y-Z$ plane; (b) Changes in the Cluster barycenter position during the crossings with respect to the neutral sheet $\left(Z^{*}=0\right)$; (c) Reconstructed current density profiles.

Using estimates of $Z^{*}$ we reconstructed the current density profiles during both crossings (Fig. 2c). Both profiles are single-peak, shifted by $1000 \mathrm{~km}$ from $B_{x}=0$ during the first crossing and centered at the neutral sheet for the second one. The current sheet during both crossings was sufficiently thin with a half-thickness of $1500 \mathrm{~km}$. These results can be simply verified by visual inspection of the $B_{x}$ time series (Fig. 1, upper panel): At the instance $\sim 140 \mathrm{~s}$, first crossing, Cluster 2 detects $B_{x}=0$ while Cluster 1 detects $B_{x}=15 \mathrm{nT}$, which is roughly half of the lobe field value. Thus, the distance between these two spacecraft $(1500 \mathrm{~km})$ gives an estimate of the current sheet half-thickness.

\section{Statistical survey}

Figure 3 shows the spacecraft locations during neutral sheet crossings for the selected 78 cases. We use aberrated GSM coordinates (see, e.g., Hori et al., 2000)
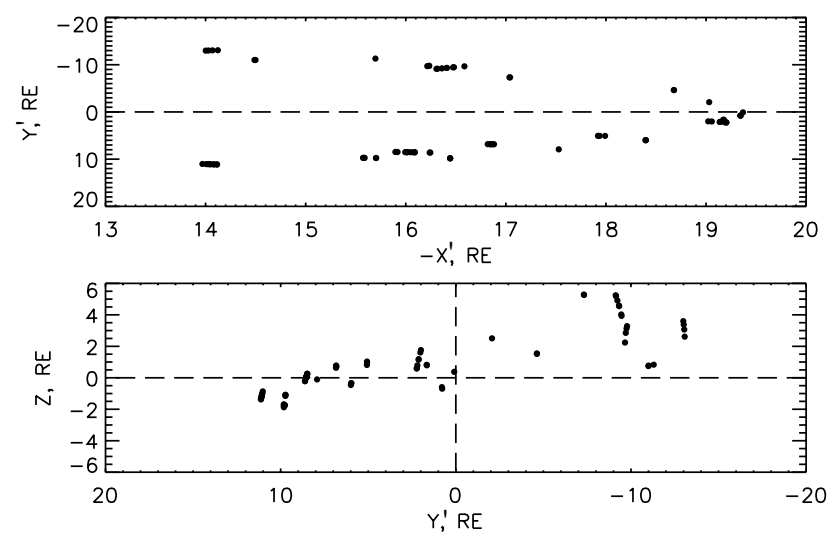

Fig. 3. Neutral sheet position $\left(B_{x}=\min \left(\left|B_{x}\right|\right)\right.$ at the Cluster barycenter) projections onto $X^{\prime}-Y^{\prime}$ and $Y^{\prime}-Z$ planes for the 78 selected cases $\left(X^{\prime}, Y^{\prime}\right.$ - aberrated GSM coordinates, see explanation in the text).
1. $X^{\prime}=X \cos \left(3.5^{\circ}\right)-Y \sin \left(3.5^{\circ}\right)$ and
2. $Y^{\prime}=X \sin \left(3.5^{\circ}\right)+Y \cos \left(3.5^{\circ}\right)$.

The cases are distributed within $-12<Y^{\prime}<12 R_{E}$ and $-2<Z<5.5 R_{E}$. Following seasonal changes, the neutral sheet crossings are asymmetrically distributed in the $Y^{\prime}-Z$ plane: During July-August (morning sector, $Y^{\prime}<0$ ) the neutral sheet was, on average, $\sim 3 R_{E}$ above the $Z=0$ plane, and during October (evening sector, $Y^{\prime}>0$ ) the neutral sheet positions are located below the $Z=0$ plane. The position of the neutral sheet at midnight was slightly above $\left(1.5-2 R_{E}\right)$ the nominal magnetic equator. A detailed analysis of seasonal changes of the neutral sheet geometry using Cluster 20012003 data was performed by Petrukovich et al. (2005).

\subsection{Plasma properties}

Figure 4 shows the distributions of average ion density (top panel, $N_{\mathrm{H}^{+}}$: crosses, $N_{\mathrm{H}^{+}}+N_{\mathrm{O}^{+}}$: circles), ion temperature (middle panel, $T_{\mathrm{H}^{+}}$only) and maximum and median $\mathrm{H}^{+}-$ion bulk horizontal velocities $V_{e q}=\sqrt{V_{x}^{2}+V_{y}^{2}}$ (CISCODIF data from Cluster 1 and 4 are used for the statistical analysis). To avoid any influence of PSBL samples (where counter-streaming beams could lead to an apparent high parallel temperature; see e.g., Baumjohann et al., 1988), the average values were calculated using samples with corresponding $\left|B_{x}\right|<0.5 B_{L}$, where $B_{L}$ is the lobe magnetic field, $B_{L}=\left(B^{2}+2 \mu_{0} P_{i}\right)^{1 / 2}$, where $P_{i}$ is the total ion pressure, calculated as the sum of $\mathrm{H}^{+}$and $\mathrm{O}^{+}$pressures.

The ion density varies between 0.1 and 3.2 with the maximum occurrence rate at $N_{i} \sim 0.4 \mathrm{~cm}^{-3}$. Three cases with an ion density less than $0.1 \mathrm{~cm}^{-3}$ at $Y^{\prime} \sim 7 R_{E}$ were observed during the 1 October 2001 storm, when the plasma sheet was mainly populated by $\mathrm{O}^{+}$ions (Kistler et al., 2005). Four cases with extremely high ion density up to $3.2 \mathrm{~cm}^{-3}$ at $Y^{\prime} \sim 2 R_{E}$ were observed on 14 September 2001, during a long period of northward IMF (Petrukovich et al., 2003). 


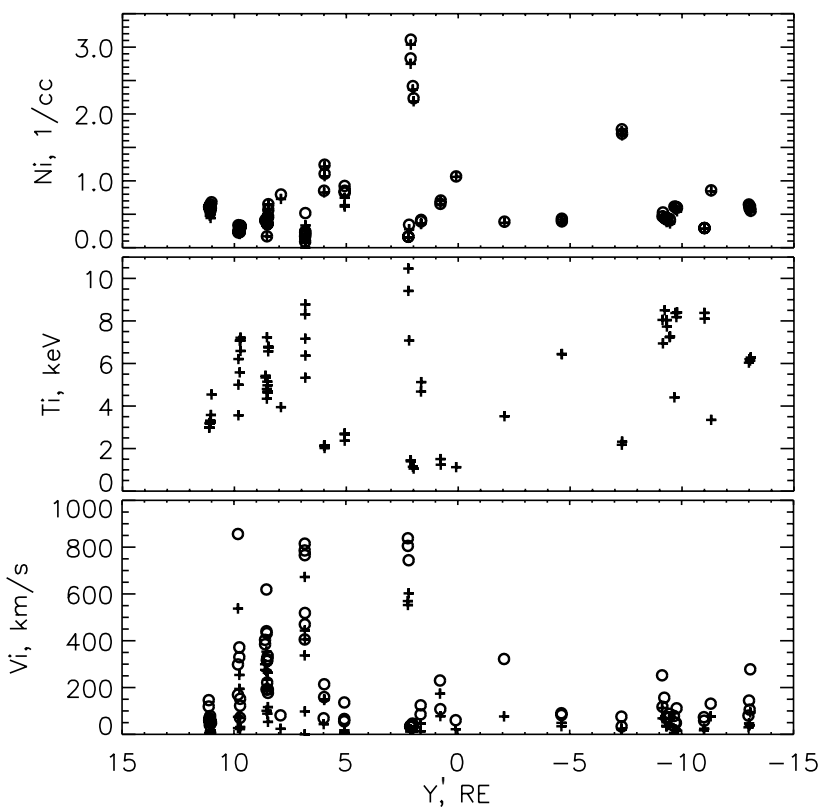

Fig. 4. Distributions of average ion density $\left(N_{\mathrm{H}^{+}}\right.$: crosses, $N_{\mathrm{H}^{+}}+$ $N_{\mathrm{O}^{+}}$: circles, upper panel), $\mathrm{H}^{+}$temperature (mid panel), average (crosses) and maximal (circles) horizontal velocities $\left(V_{x y}\right)$ for each selected crossing versus $Y^{\prime}$.

The ion temperature varies in a wide range from $T_{i} \sim 2 \mathrm{keV}$ to $T_{i} \sim 10 \mathrm{keV}$. Therefore, our database includes a broad spectrum of plasma conditions ranging from a hot rarified plasma sheet to a cold dense one.

In 52 of the 78 cases the average horizontal ion bulk velocity $\left(V_{x y}\right)$ was less than $100 \mathrm{~km} / \mathrm{s}$, in 17 cases it ranged between $100<V_{x y}<300 \mathrm{~km} / \mathrm{s}$. In more than $60 \%$ of the cases (50 out of 78) the maximum ion bulk velocity was less than $200 \mathrm{~km} / \mathrm{s}$. High-speed horizontal flow with $V_{x y}>400 \mathrm{~km} / \mathrm{s}$ was detected in 14 cases (maximum velocities were counted). All of them were observed in the pre-midnight half of the magnetotail. Therefore, the majority of crossings represents low velocity events.

\subsection{Orientation and motion}

To survey the current sheet orientation and motion, we used timing analysis of the magnetic field time series.

Figure 5 shows a distribution of $Y$ - and $Z$-components of the current sheet normal velocity of the current sheet, resulting from timing, (upper panel) and projections of the normal velocity onto the $X^{\prime}-Y^{\prime}$ plane (bottom panel). The results show that in most cases the current sheet normals lay in the $Z-Y$ plane, where the $X$-components of the normal vectors are smaller than its $Y$ and $Z$ components, therefore, points are close to a unit circle in the $N_{Y}-N_{Z}$ plane. Moreover, in 69 cases $(89 \%)$ the normal velocities have a negative $Y$ component in the post-midnight sector, and a positive $Y$ component in the pre-midnight sector. The $X^{\prime}-Y^{\prime}$-projections of the normal velocity (Fig. 5, bottom panel) show that most of

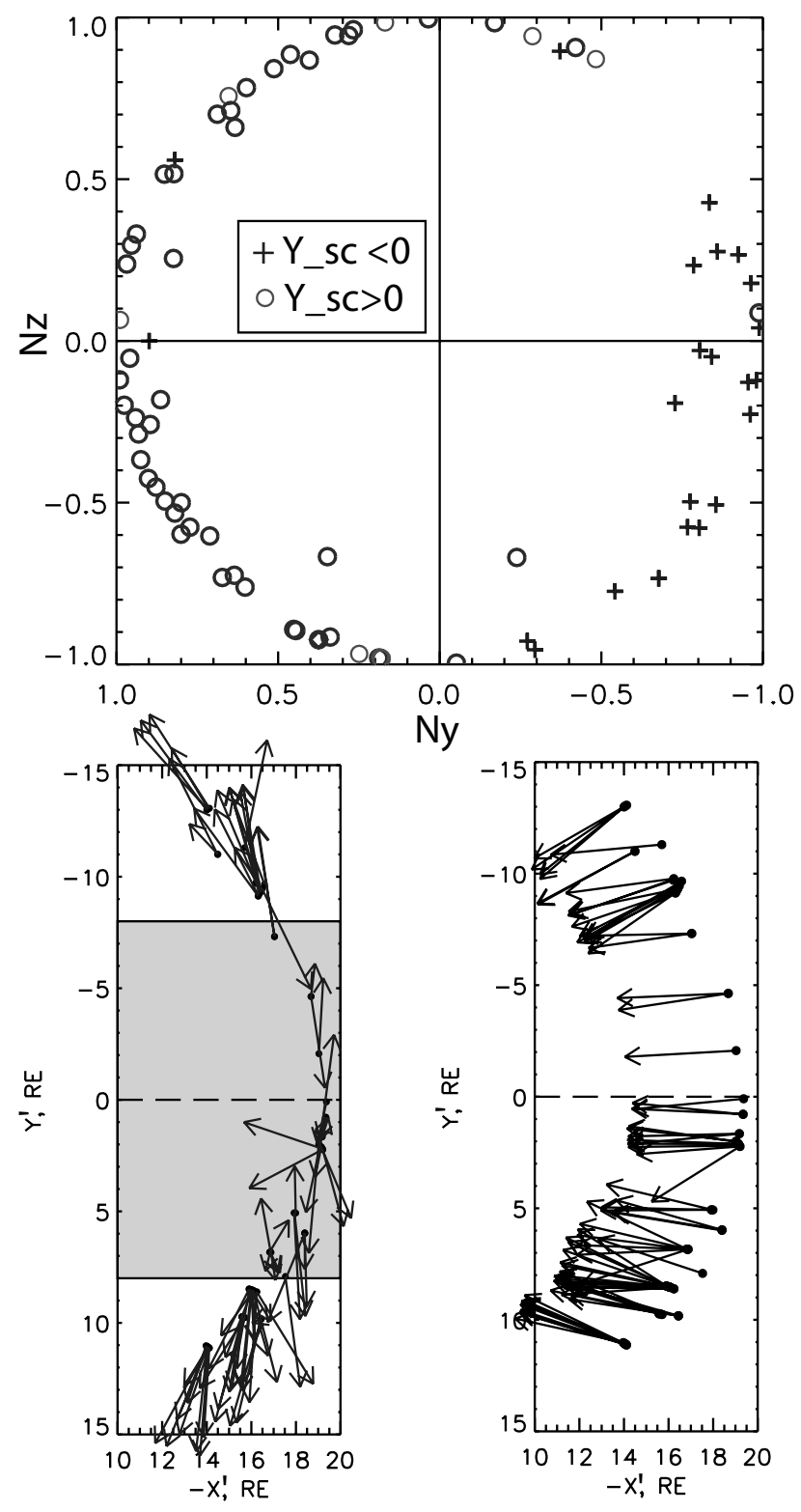

Fig. 5. Distribution of $Y$ and $Z$ components of the normal velocity $\mathbf{V}_{n}$ resulting from timing analysis of current sheet crossings in the post-midnight (crosses) and the pre-midnight (circles) sectors (upper panel) and projections of $\mathbf{V}_{n}$ onto the $X^{\prime}-Y^{\prime}$ (left-hand bottom panel), the shadowed box indicated the area omitted by Sergeev et al. (2004); Right-hand bottom panel: Projections of maximum variance MVA eigenvectors onto the $X^{\prime}-Y^{\prime}$ plane.

the exceptions came from the pre-midnight part of the nearmidnight sector $\left(0 \leq Y^{\prime} \leq 7 R_{E}\right)$.

The right-hand bottom panel of Fig. 5 shows the projections of maximum variance MVA eigenvectors. Comparison of the two bottom plots shows that the current sheet structures (like in Fig. 2) are propagating basically perpendicular to the main magnetic field.

Using timing analysis we estimate normal velocities of the kink fronts and scales (half-thickness) of the structures, 

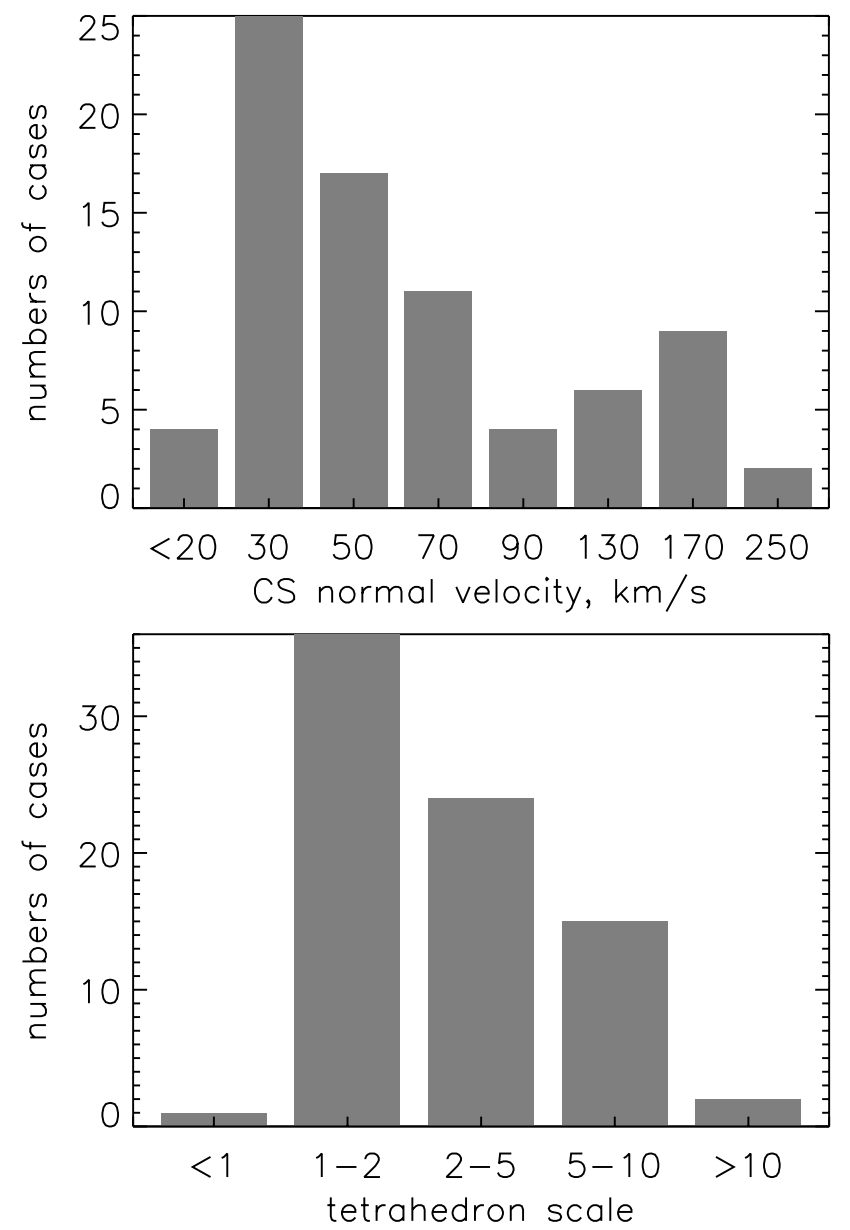

Fig. 6. Occurrence rates of the current sheet normal velocity $\left(V_{n}\right.$, from timing) and estimated scales $s=V_{n} \cdot \tau$, where $\tau$ is a crossing duration, normalized to characteristic tetrahedron scale $a$.

$S_{h}=V_{n} \tau$, where $\tau$ is a crossing duration from $B_{x}=0$ to $B_{x}=\max \left|B_{x}\right|$. The results are presented in Fig. 6. In 53 cases $(68 \%)$ the normal velocity of the sheet was low, between 30 to $70 \mathrm{~km} / \mathrm{s}$. Only 17 cases with velocities between $100-300 \mathrm{~km} / \mathrm{s}$ were found. The corresponding thickness of the structures varied from $1500 \mathrm{~km}$ to $10000 \mathrm{~km}$, with the maximum occurrence at $2000-3000 \mathrm{~km}$. The bottom panel of Fig. 6 shows the occurrence rates of the estimated scales, normalized to the characteristic scales of the tetrahedron $2 \mathrm{a}$ (see Robert et al., 1998b), calculated for each crossing time $t_{0}$. The ratio $S_{h} /(2 a)>1$ in $99 \%$ and $S_{h} /(2 a)>3$ in more than $50 \%$ of the cases. Therefore, the use of the linear gradient estimator technique is justified for most of the crossings in our database.

\subsection{Electric currents in the neutral sheet}

To survey the directions of electric currents we calculated the current unit vector $\mathbf{e}_{\mathbf{j}}=\nabla \times \mathbf{B} /|\nabla \times \mathbf{B}|$ in the neutral sheet $\left(\left|B_{x}\right|<5 \mathrm{nT}\right)$. The distribution of $Y$ - and $Z$-components of $\mathbf{e}_{j}$ is shown in Fig. 7 (upper panel). The electric current directions are equally distributed in the $e_{j Y}>0$ half-plane, indi-

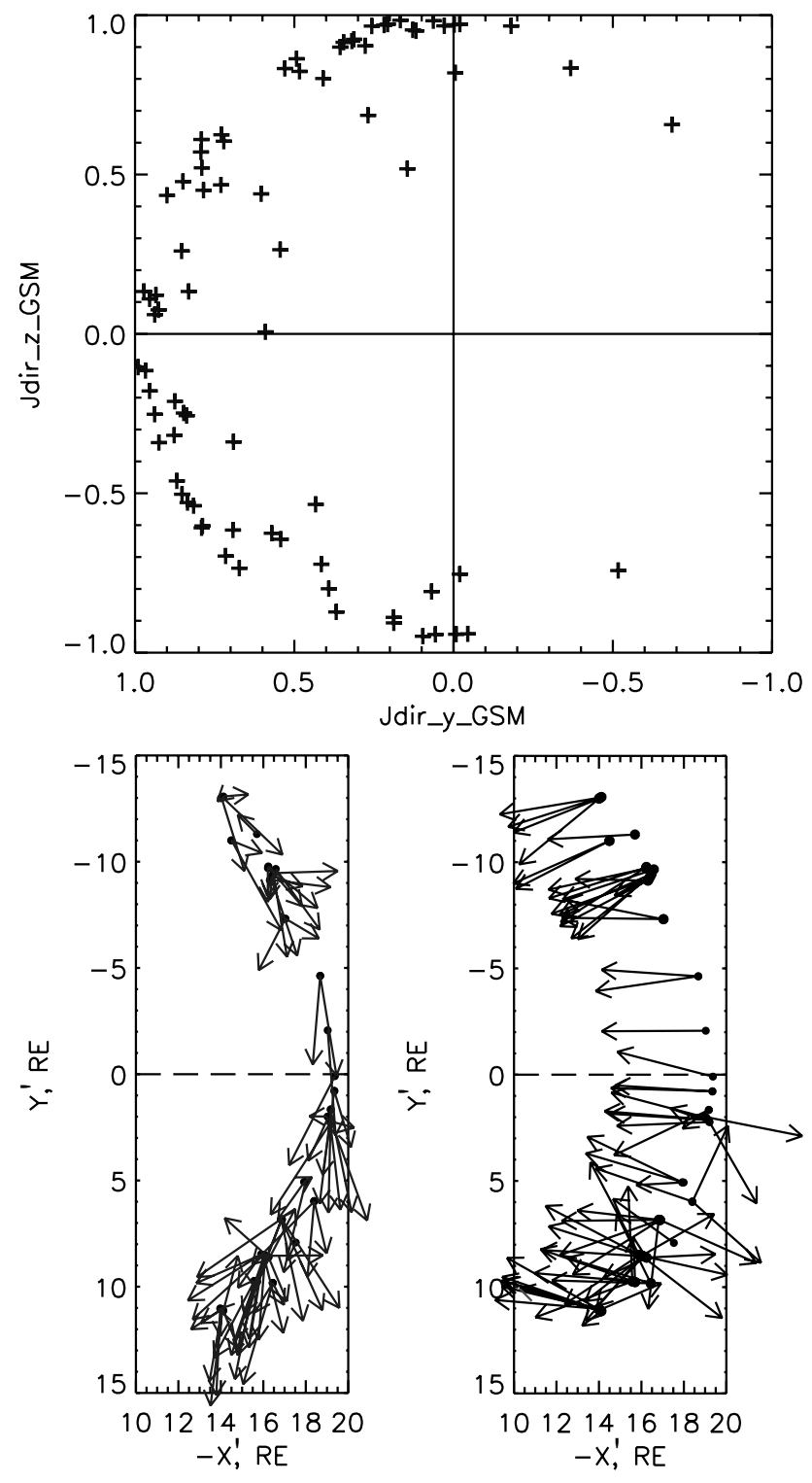

Fig. 7. Electric current and curvature directions. Upper panel: Distribution $Y$ and $Z$ components of the unit vectors $\mathbf{e}_{j}=\mathbf{j} / j$; Bottom panels: Projections of $\mathbf{e}_{j}$ (left-hand panel), and projections of $\mathbf{e}_{C}=\mathbf{C} / C$ (right-hand panel) onto the $X^{\prime}-Y^{\prime}$ plane.

cating that electric currents often deviate from the nominal dawn-dusk direction during current sheet flapping events, as in Fig. 2. There are four events with a significant negative $Y$ component of $\mathbf{e}_{j}$. This may be explained by an increase in the kink front steepness up to its overturn, similar to the situation described by Zhang et al. (2002).

The left-hand bottom panel in Fig. 7 shows projections of the electric current direction in the $X^{\prime}-Y^{\prime}$ plane. The electric current basically has a negative $X$-component in the morning sector and a positive one in the evening sector. An occurrence rate analysis shows that in the post-midnight sector in 7 cases from $23 e_{j_{x}}>0$ and in 16 cases $e_{j_{x}} \leq 0$; in the pre-midnight sector in 37 cases $e_{j_{x}} \geq 0$ and in 18 cases $e_{j_{x}}<0$. Therefore, 
predominantly, the neutral sheet current is directed, as expected, perpendicular to the flaring tail magnetic field.

Projections of the normalized magnetic field curvature vectors $\mathbf{e}_{C}=\mathbf{C} / C$, where $\mathbf{C}=(\mathbf{b} \cdot \nabla) \mathbf{b}$ onto the $X^{\prime}-Y^{\prime}$ plane are shown in Fig. 7, right-hand bottom panel. The curvature displays the corresponding behaviour. In most of the cases (68 of 78) the magnetic field curvature vectors are directed earthward $(X>0)$, as expected on closed magnetic field lines of the plasma sheet. In 10 cases $C_{x}<0$; the negative curvature means that Cluster is situated on magnetic loops or tailward of the reconnection region. All these situations in our database are detected in the pre-midnight sector. In the post-midnight sector in 19 cases $C_{y} \geq 0$ and in 4 cases $C_{y}<0$; in the pre-midnight sector $C_{y} \leq 0$ in 34 cases and $C_{y}>0$ in 21 cases.

In order to examine the mutual orientation of the maximum variance eigenvectors $\mathbf{l}$, the current sheet normals $\mathbf{n}_{t}$, defined by timing analysis, and the electric current directions $\mathbf{e}_{j}$, we compare their dot products and $\mathbf{n}_{t} \cdot \mathbf{n}_{j}$, where $\mathbf{n}_{j}=\mathbf{l} \times \mathbf{e}_{j}$. The results are shown in Fig. 8 .

Data points cluster around the point $(0,1)$ on both panels, indicating the expected relationship between these directions: The timing normals are generally orthogonal to the maximum variance eigenvector and collinear to $\mathbf{n}_{j}$. At the same time, the difference between $\mathbf{n}_{t}$ and $\mathbf{n}_{j}$ is not negligible: Only for $32 \%$ of cases are the angles between these two normals are less than $15^{\circ}$, and for $76 \%$ of the cases are they less than $30^{\circ}$. This difference stems mainly from nonorthogonality of $\mathbf{e}_{j}$ and $\mathbf{l}$ (Fig. 8, right-hand panel).

\subsection{Characteristic scales}

To estimate the amplitude of the current sheet flapping we calculate $Z^{*}$ according to Eq. (2). All events were visually inspected to exclude cases with non-monotonous changes in $Z^{*}$ with time. Only 67 crossings are suitable for the scale estimation. For these cases the characteristic gradient scales $h$ were estimated as the half-thickness of the $j\left(Z^{*}\right)$ profile. Distributions of the flapping amplitude $S=\left|\max \left(Z^{*}\right)\right|$ and the scale $h$ versus $Y^{\prime}$ are shown in Fig. 9 (upper panel). Another characteristic of the current sheet scale could be the median value of the magnetic field curvature radius in the neutral sheet $\left(R_{c e q}\right)$ and minimum $R_{c}$ value, averaging $R_{c}$ values within $8 \mathrm{~s}(\sim 2 \mathrm{spacecraft}$ spins) around the actual minimum of $R_{c}$ during each crossing. The middle panel shows the distribution of the median in the neutral sheet (equatorial $R_{c}$ ) and minimum values of the magnetic field curvature radius $R_{c}$, calculated for the selected 67 crossings versus $Y^{\prime}$. The results show that both flapping amplitude and scale $h$ have a tendency to increase toward the flanks. For the magnetic field curvature radius this tendency is less pronounced. Only a very weak correlation $(\mathrm{R} \sim 0.2)$ between the current sheet scales $h$ and the median curvature radii was found.

An alternative way to obtain a proxy of the current sheet half-thickness is a fit to the Harris function $B_{x}=B_{L} \tanh (Z / \lambda)$ using the lobe field $B_{L}$ and the estimated gradient of the mag-
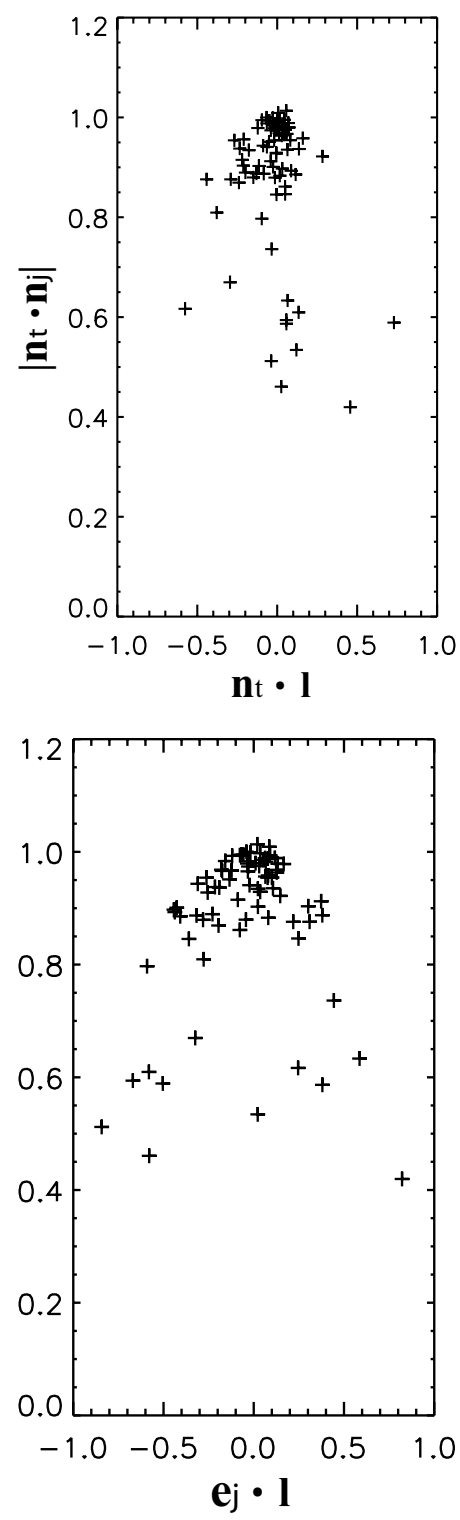

Fig. 8. Mutual orientation of the main magnetic field direction $\mathbf{l}$, timing normal $\mathbf{n}_{t}$, and $\mathbf{n}_{j}=\mathbf{l} \times \mathbf{j} / j$.

netic field. The Harris scale $\lambda$ results from the calculation of $\partial B_{x} / \partial Z$, expressed in the current sheet coordinate system as

$\lambda=\frac{B_{L}}{\nabla_{n} B_{l}}\left[1-\left(\frac{B_{l}}{B_{L}}\right)^{2}\right]$,

where $B_{l}$ is the main component of the magnetic field, and $\nabla_{n}$ is the component of the magnetic field gradient along the normal. For the 64 selected crossings we estimate $\langle\lambda\rangle$ using median value of $\nabla_{n} B_{l}$. The relative standard deviation $\sigma(\lambda) / \lambda$ varies in between 0.07 and 2.7. On average, the Harris scale $\lambda$ is a factor of 2 larger than the scale $h$, see Fig. 9 (bottom panel).

Figure 10 shows the occurrence rates of the current sheet half-thicknesses $h$, magnetic field curvature radii in the neutral sheet (equatorial $R_{c}$ ), and minimum $R_{c}$. The estimates 

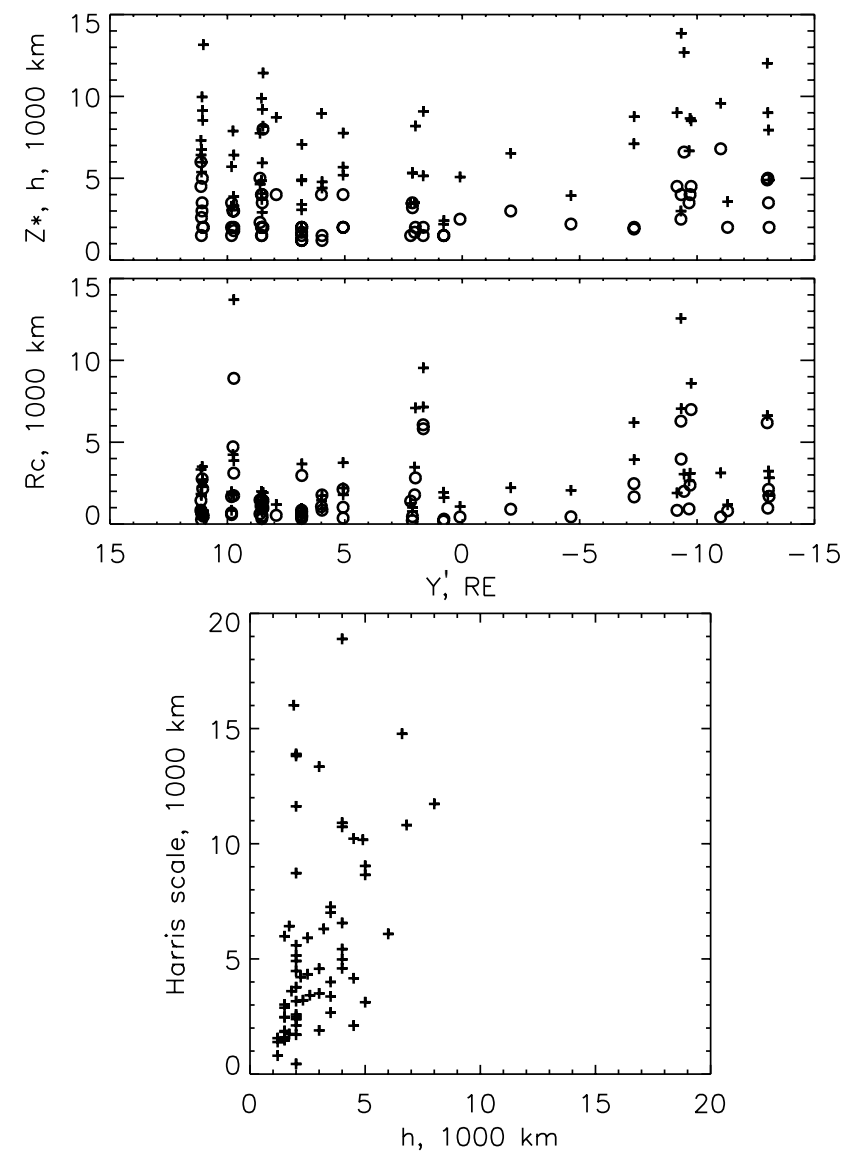

Fig. 9. Distributions of flapping amplitude (crosses), current sheet half-thicknesses (circles) and median radii of the magnetic field curvature in the NS ( $R_{c e q}$, crosses) and minimum $R_{C}$ (circles) versus $Y^{\prime}$ (upper panel); Bottom panel: Comparison of gradient scales $h$, calculated according to Eq. (2) and Harris scales, Eq. (3).

of $h$ and $R_{c}$ are normalized to a characteristic plasma scale (the proton thermal gyroradii $L_{c p}$, calculated from proton temperature, averaged for each crossing using samples with $\left|B_{x}\right|<0.5 B_{L}$, and the lobe magnetic field $\left.B_{L}\right) . L_{c p}$ varied between 130 and $700 \mathrm{~km}$ with a mean value of $343 \mathrm{~km}$. The half-thickness $h$ varies within a rather wide range of $L_{c p}$ : In 38 cases out of $67(57 \%)$ the current sheet was relatively thin with $1<Z^{*} / L_{c p}<10$, and in 29 cases $Z^{*} / L_{c p}>10$. No relationship was found between the scale estimates $h$ and the current sheet tilt. The most frequent value of minimum $R_{c}$ varies in between 1-5 ion thermal gyroradii $\left(L_{c p}\right)$, but the most frequent median value of $R_{c}$ in the neutral sheet is between 1-10 $L_{c p}$.

Figure 11 presents distributions of median magnetic field in the neutral sheet $B_{N S}=\sqrt{\left\langle B_{y}\right\rangle^{2}+\left\langle B_{z}\right\rangle^{2}}(\langle\rangle$ denotes averaging within $\left.\left|B_{x}\right|<5 \mathrm{nT}\right)$, and the adiabaticity parameter $\kappa=\sqrt{\min \left(R_{c}\right) / \rho_{p}}$, where $\rho_{p}=L_{c p} B_{N S} / B_{L}$ is the proton thermal gyroradius in the neutral sheet. $B_{N S}$ varies between 1.0 and $18.1 \mathrm{nT}$ with the median value of $3.6 \mathrm{nT}$. The $\kappa$ parameter is generally smaller than unity (median value is 0.6 ) which indicates a non-adiabatic motion of protons in the flap-
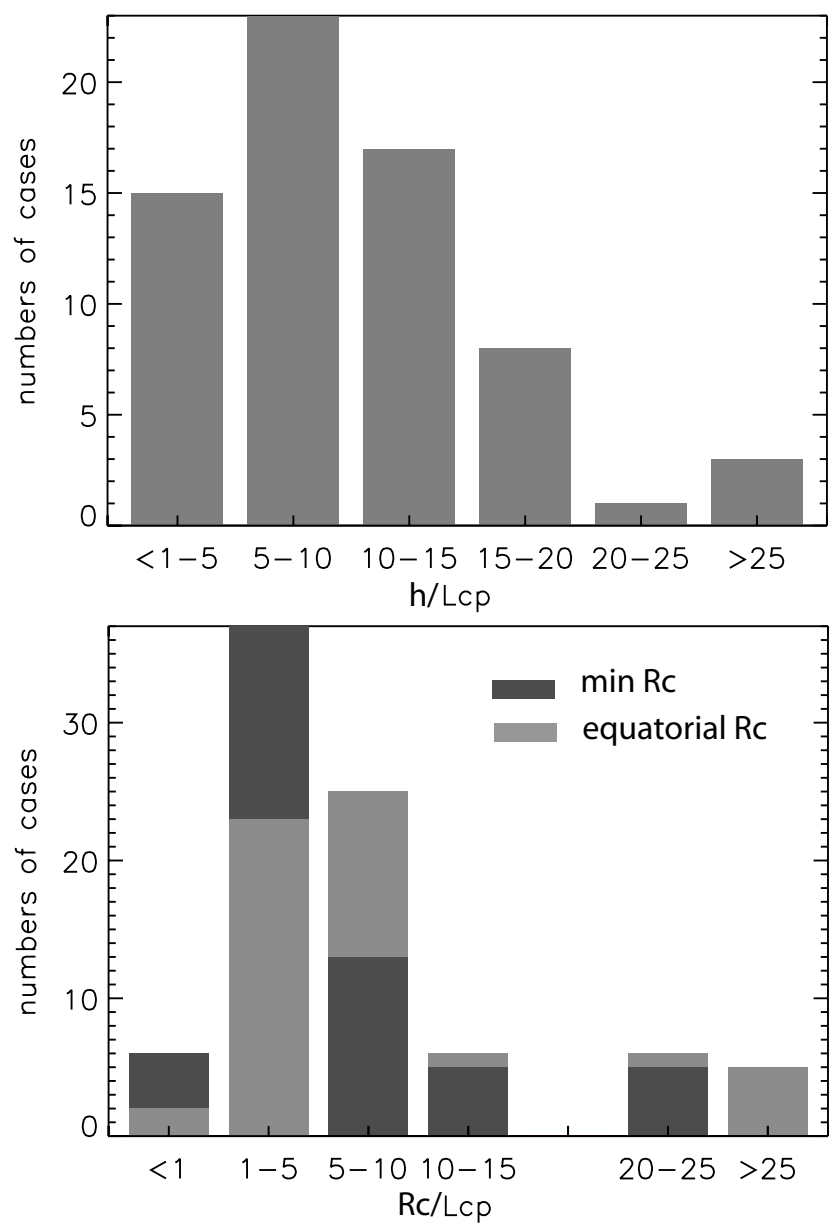

Fig. 10. Occurrence rates of current sheet half-thicknesses $h$ and magnetic field curvature radii $R_{C}$ (minimum and median in the NS). $h$ and $R_{C}$ are normalized by the characteristic plasma scale $L_{c p}$ (see details in text).
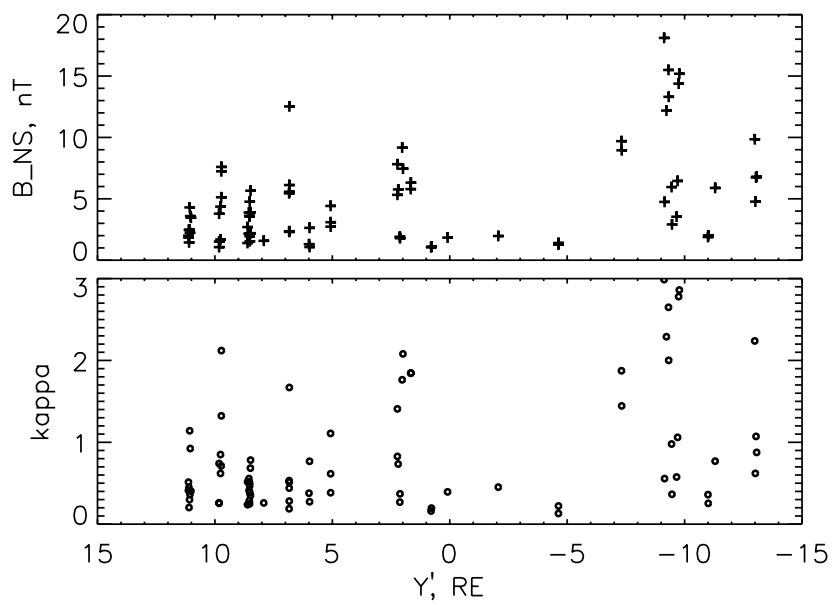

Fig. 11. Distributions of the median magnetic field in the neutral sheet $B_{N S}$ (upper panel) and the adiabaticity parameter $\kappa$ (bottom panel) versus $Y^{\prime}$. 

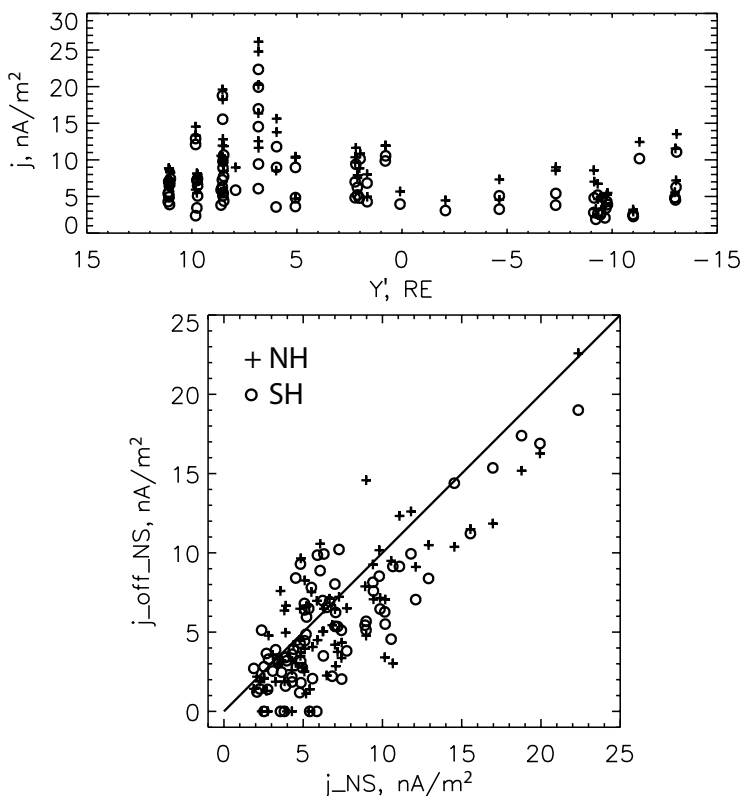

Fig. 12. Upper panel: Distributions of the maximum current density (crosses) and median current density in the NS (circles). Bottom panel: Distribution of median values of $|j|$ in the NS and out of the NS.

ping current sheet. Both $B_{N S}$ and $\kappa$ have a tendency to be more scattered in the post-midnight sector than in the premidnight. No pronounced statistical relationship between the $\kappa$-parameter and the current sheet half-thickness was found ( $\mathrm{R}=0.15)$.

Figure 12 shows distributions of the maximum and median current density within the neutral sheet $\left(\left|B_{x}\right|<5 \mathrm{nT}\right)$ for 78 crossings (upper panel). As it was mentioned in Sect. 2, the current density value may be underestimated by up to $30 \%$, and values shown in Fig. 12 rather give their lower estimates. The most frequent current density value varies between 5 and $10 \mathrm{nA} / \mathrm{m}^{2}$. There is a tendency for the current to be stronger in the dusk sector than at dawn. The largest current density in our database was observed during a strong storm-time substorm on 1 October 2001 (Runov et al., 2003a; Kistler et al., 2005).

To characterize the current density distribution in the sheet we compared the mean values of the current density within the neutral sheet $\left(j_{N S}\right)$ and outside the neutral sheet $\left(j_{o f f-N S}\right)$ for the northern $\left(\mathrm{NH}, 5<B_{x}<15 \mathrm{nT}\right)$ and the southern $\left(\mathrm{SH},-15<B_{x}<-5 \mathrm{nT}\right)$ halves of the current sheet (Fig. 12, bottom panel). In $55 \%$ of the selected crossings (43 of 78) the current density is larger in the neutral sheet: $\left.\langle|j|\rangle_{N S}\right\rangle\langle|j|\rangle_{o f f-N S}$, in the remaining 35 cases the current density distribution is off-center. Eight out of these 35 cases show a bifurcated current sheet: The mean value of the current density in the southern half is comparable with the current density in the northern half, namely, $\langle|j|\rangle_{S H}<\langle|j|\rangle_{N H} \cdot(1 \pm 0.25)$. In the other 27 cases the current sheet is asymmetric with a larger current density in one hemisphere.

\section{Discussion}

The statistical survey of rapid crossings of the magnetotail current sheet shows that Cluster mainly crosses corrugations of the sheet surface, similar to the one shown in Fig. 2. The current sheet normal $\mathbf{N}$ is tilted in the $Y-Z$ plane; according to the timing analysis, in $54 \%$ of the cases studied the tilt angle $\phi=\operatorname{atan}\left(\left|N_{y}\right| /\left|N_{z}\right|\right)>45^{\circ}$. These kink-type waves, responsible for the sheet's corrugation, mainly propagate dawnward in the post-midnight sector and duskward in the pre-midnight one, as was shown by Sergeev et al. (2004) using only the data from near-flank crossings. Inclusion of the near-midnight sector $|Y|<8 R_{E}$, omitted in the previous study, generally does not change this conclusion. However, most of the exceptions are located in the evening half of the near-midnight sector with $0 \leq Y^{\prime} \leq 7 R_{E}$ (Fig. 5). As follows from the timing analysis the flapping wave fronts move mainly perpendicular to the main magnetic field direction, except for several cases within $0 \leq Y^{\prime} \leq 7 R_{E}$. Their normal velocities vary between a few tens and $300 \mathrm{~km} / \mathrm{s}$.

The study of the electric current direction during flapping confirms the timing results: In $51 \%$ of the cases the angle between the $Z=0$ plane (nominal position of the neutral sheet) and the calculated current density direction is larger than $45^{\circ}$. In 44 cases $j_{Z}$ was positive and in the other $34 j_{Z}<0$. The directions of $\mathbf{j}$ are mainly perpendicular to the normal obtained from the timing analysis. Therefore, the electric current geometry, described in the example case (Fig. 2) seems to be common, confirming that flapping is not a simple up-down motion of a planar current sheet with dawn-dusk directed current, but is due to current sheet corrugations, moving toward the flanks perpendicular to the main magnetic field. Some caution follows from this result: The properties of the current sheet observed during flapping are properties of the kinking current sheet, and they may be different from properties of a normal current sheet.

Values of the current density resulting from the linear estimation of the $\nabla \times \mathbf{B}$ are underestimated, because of the relatively large inter-spacecraft separation during the 2001 tail period, however, typically they are by a factor of 2 larger than the values obtained by analysis of longer crossings (3.5 $\mathrm{nA} / \mathrm{m}^{2}$, Zhang et al., 2005) and statistical values of the current density in the plasma sheet, calculated from measured ion and electron moments $\left(1-3 \mathrm{nA} / \mathrm{m}^{2}\right.$, Kaufmann et al., 2001).

Comparing the current density within and outside the neutral sheet, we found that the current sheet during flapping is often off-center: The main part of the current is shifted from the neutral sheet to the northern or southern half of the sheet. A simple check of symmetry, a comparison between median current density in the Northern and Southern Hemispheres, shows that most frequently the current density has an asymmetric distribution. Similar analysis, performed by Asano et al. (2005) for non-flapping intervals, yields off-central current density distribution only in $\sim 20 \%$ of the events. Thus, asymmetry seems to be a feature of the kink-like waves, and 
is most likely a temporal effect rather than a stable feature of the current sheet.

The magnetic field curvature is an important factor controlling particle and wave motions in the current sheet. Our study shows that the kink-like waves, responsible for flapping, mainly propagate in a magnetic field with positive $\left(C_{x}>0\right.$ - earthward) curvature, that is on closed field lines, with minimum curvature radii varying from $\sim 500$ to $10000 \mathrm{~km}$. Generally, this agrees with the values reported by Shen et al. (2003).

The fact that the flapping waves propagate through a curved magnetic field may be crucial for understanding the driving mechanism of this kinking. Indeed, neither KelvinHelmholtz (Nakagawa and Nishida, 1989; Ricci et al., 2004) nor ion-ion kink (Karimabadi et al., 2003) waves propagate in opposite $( \pm Y)$ directions from the midnight region. The investigation of MHD eigenmodes of the Harris-type current sheet without a normal component (e.g., Lee et al., 1988; Louarn et al., 2004) also did not provide a solution. However, ballooning-like waves, generated in a curved magnetic field, can possibly propagate in opposite $Y$ directions (Golovchanskaya and Maltsev, 2004). It should be emphasized that flapping is most likely associated not with regular harmonic waves, but with a set of isolated kinks, as shown in Sect. 2 . Moreover, they exhibit properties of strongly nonlinear oscillations, i.e. their amplitudes have the same order of magnitude as the thickness of the sheet, and wave front oversteepness does not seem rare.

Excitation of large amplitude nonlinear kink waves with phase velocity an order of magnitude less than the thermal ion speed have been reported in PIC simulations of the bifurcated current sheet (Sitnov et al., 2004). These kinks, developing from the instability of the thin bifurcated current sheet, can be transported by plasma flow. The current sheet bifurcation was observed in $10 \%$ of selected cases. We found a weak correlation between the $Y$-component of the average ion velocity and the $Y$-component of the front velocity: The correlation coefficient in the morning sector was $\mathrm{R}=0.64$, and in the evening sector R $\sim 0.5$ (only cases with $V_{x y}<200 \mathrm{~km} / \mathrm{s}$ were taken into account). The slope of the linear regression was near unity in both sectors. Correlations between $Z$ components of ion and front velocities are much weaker (near 0.3 ) in both sectors.

Crossings with negative (tailward) curvature, most likely associated with reconnection, were detected in the evening part of the near-midnight sector. High speed ion flows (see Fig. 4), both earthward and tailward, were also detected in the same part of the magnetotail. This agrees with the most probable location of substorm onsets $\left(0<Y<8 R_{E}\right.$, Nagai et al., 1998). It is interesting to note that the exceptions from the main rule (propagation from midnight toward flanks, see Fig. 5) are also concentrated in this region of the magnetotail. Therefore, sources of the flapping waves, are most likely situated within $0 \leq Y \leq 7 R_{E}$. However, more detailed analysis, including simulations, are needed to verify this observation.

According to our statistical analysis, the minimum radius of magnetic field, curvature is comparable with the charac- teristic plasma scale $L_{c p}$ and the median value of $R_{c} / L_{c p}$ in the neutral sheet $R_{c e q} \sim 1-10$. The magnetic field in the neutral sheet ranges between $0<B_{n s}<7 \mathrm{nT}$, and the parameter $\kappa$ is less than unity for the largest part of the selected crossing, indicating the non-adiabatic character of ion motion in the neutral sheet vicinity (e.g., Büchner and Zelenyi, 1989). However, several crossings with a large curvature radius $R_{c} / L_{c p} \geq 20$ were also found.

The half-thickness of the current sheet during flapping varies in a broad range from 1 to $20 L_{c p}$, with a maximum occurrence rate at 5-10 $L_{c p}$. We found no statistical relationship between the current sheet half-thickness and the tilt of the normal.

No close relationship between the minimum curvature radius and the current sheet half-thickness was found. Therefore, the minimum curvature radius should not be used as a proxy of the current sheet half-thickness, as was suggested by Shen et al. (2003).

\section{Conclusions}

The analysis of the magnetic field geometry, plasma, and electric current characteristics was done for 78 rapid crossings of the magnetotail current sheet during July-October 2001. We found that:

1. Most of the rapid crossings are due to kink-like transients passing over the spacecraft. The normals to the kink fronts are tilted in the $Y-Z$ plane. The electric currents exhibit corresponding behavior. The kinks fronts are often close to vertical with $\left|j_{z}\right|>j_{y}$, and sometimes over-steepened $\left(j_{y}<0\right)$. They exhibit properties of nonlinear waves.

2. The half-thickness of the current sheet during flapping varies from $\sim 1$ to 20 ion thermal gyroradii (calculated using the lobe magnetic field). No relationship between half-thickness and tilt of the normal was found. Thus, kinking is not a feature of thin current sheets only. In 68 out of 78 cases, the magnetic field curvature vector was directed earthward (positive curvature). The minimum curvature radius varies between 500 and $10000 \mathrm{~km}$, showing no close relationship with the sheet half-thickness estimation. In $73 \%$ of the crossings the adiabaticity parameter $\kappa$, ruling ion motion in the current sheet, is less than unity.

3. Kinking current sheets often have off-center and asymmetric current distribution across the sheet, so that the main current is shifted from the neutral sheet. This seems to be a dynamic feature associated with the flapping.

\section{Appendix A}

To test the accuracy of the current sheet structure reconstruction described in Sect. 2, we performed a set of test 

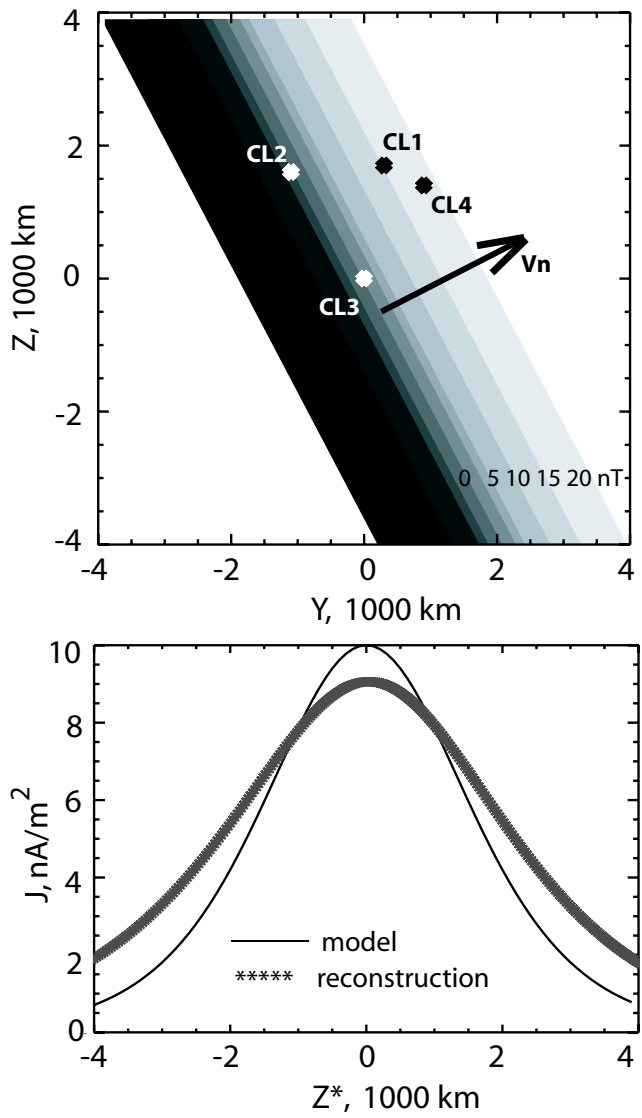

Fig. A1. Upper panel: Model of flapping motion of 1-D current sheet, magnetic field intensity is gray-scale coded. Bottom panel: Model (solid line) and reconstructed (asterisks) profiles of current density.

calculations using a kinematic model of the current sheet. To simplify the calculations we used the 1-D Harris-type model: $B_{x}=B_{0} \tanh \left(Z_{n} / \lambda\right), B_{y}=B_{z}=0$, where $Z_{n}$ is a coordinate along the normal to the sheet. It is assumed that such a current sheet is moving with constant velocity without rotation while keeping its structure and scale size.

In the following we use the Cluster tetrahedron configuration at 15:30 UT, 12 August 2001 (see example in Sect. 4 when the spacecraft separations relative to tetrahedron barycenter (in $\mathrm{km}$ ) were $[1021,-287,490],[-415$, $1110,410],[77,51,-1174]$ and $[-683,-874,274]$, correspondingly, for spacecraft $\mathrm{C} 1, \mathrm{C} 2, \mathrm{C} 3$ and $\mathrm{C} 4$. Thus, the semiaxes of the corresponding pseudo-ellipsoid are $\mathrm{a}=697.0 \mathrm{~km}, \mathrm{~b}=694.5 \mathrm{~km}$ and $\mathrm{c}=629.9 \mathrm{~km}$, the characteristic size $2 \mathrm{a}=1394 \mathrm{~km}$, elongation $\mathrm{E}=0.0036$, planarity $\mathrm{P}=0.0931$, and the tetrahedron geometric factor $Q_{s r}=0.95$ (see Robert et al., 1998b, for definitions).

First, we show an example of calculations for the current sheet normal corresponding to the crossing at 15:27:40 UT 12 August 2001 (see Sect. 4): $\mathbf{n}=[0.123-0.8780 .462]$. The current sheet normal is tilted by $62.3^{\circ}$ in the Y-Z plane, by $11.3^{\circ}$ in the $\mathrm{X}-\mathrm{Y}$ plane and by $14.9^{\circ}$ in the $\mathrm{X}-\mathrm{Z}$ plane - see Fig. A1 (upper panel). The model current sheet parameters

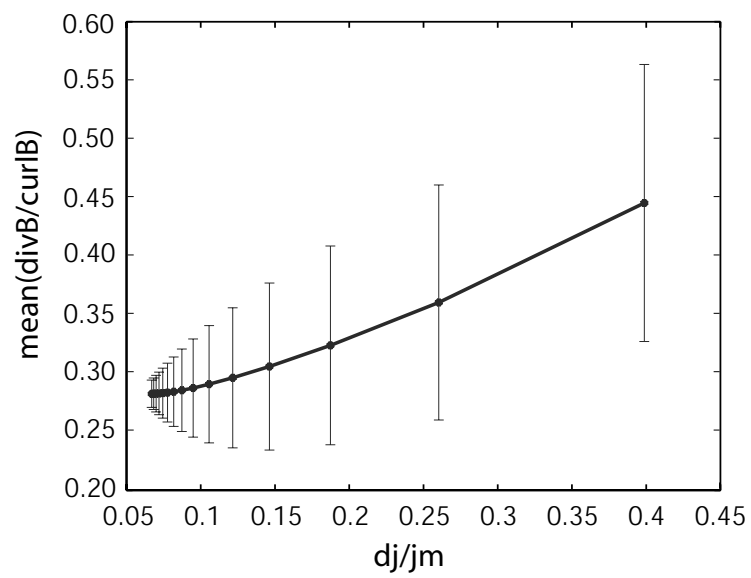

Fig. A2. Average ratio $|\nabla \cdot \mathbf{B}| /|\nabla \times \mathbf{B}|$ with standard deviations (errorbars) versus relative error of the current density estimate for model $\lambda=500-4000 \mathrm{~km}$.

are $B_{0}=20 \mathrm{nT}$ and $\lambda=2000 \mathrm{~km}$. Model normal translation velocity of the current sheet is $V_{n}=23.5 \mathrm{~km} / \mathrm{s}$. The crossing duration is $\tau=300 \mathrm{~s}$.

We first simulate the magnetic field time series from four virtual magnetometers and then calculate the tensor of the magnetic field derivatives using the linear curl estimator technique (Chanteur, 1998). Since the minimum variance analysis (MVA) cannot be applied to determine a normal vector for the Harris-type current sheet (where $\delta B_{z}=\delta B_{y}=0$ ), the sheet normal is estimated by combining MVA and curlometer results. From MVA we obtain the maximum variance eigenvector $\mathbf{l}$, which gives the direction of the main magnetic field component $B_{l}$ (in the example of Fig. A1 $\mathbf{l}=[0.957,-0.134,0.256])$. Based on the known normal direction we compute the normal component of $B_{l}$ gradient $\nabla_{n} B_{l}=\nabla B_{l} \cdot \mathbf{n}$. To reconstruct the effective vertical coordinate $Z^{*}$ we integrate the effective translation velocity $\mathbf{U}=\partial_{t} B_{l}\left[\nabla_{n} B_{l}\right]^{-1}$ in time during the crossing and set $Z^{*}=0$ where $B_{l}=\min \left(\left|B_{l}\right|\right)$.

Figure A1 (bottom panel) shows the reconstructed profile of the current density $j_{r}\left(Z^{*}\right)$ (asterisks) and the model profile $j_{m}(Z)$ (solid line). The maximum of the reconstructed current density is $\max \left(j_{r}\right)=9.06 \mathrm{nA} / \mathrm{m}^{2}$, which is by $9 \%$ smaller than the model current density maximum $\max \left(j_{m}\right)=10.0 \mathrm{nA} / \mathrm{m}^{2}$. The ratio $|\operatorname{div} \mathbf{B}| /|\operatorname{rot} \mathbf{B}|$ is $<0.30$ for $63 \%$ of simulated samples. The half-thickness of the reconstructed current density profile $H T$ (half-thickness at $\left.j_{r}=0.5 \max \left(j_{r}\right)\right)$ equals $2160 \mathrm{~km}$, with a relative error of 0.08 . The direction of the reconstructed electric current at $B_{x} \sim 0$ is $\mathbf{e}_{j r}=[-0.168,0.461,0.871]$, thus $\mathbf{n} \cdot \mathbf{e}_{j r}=0.02$ and $\mathbf{l} \cdot \mathbf{e}_{j r}=7.45 \cdot 10^{-8}$.

Applying multi-point timing analysis (Harvey, 1998) to simulated $B_{x}$ time series we obtained the effective normal vector $n^{*}=[0.117,-0.878,0.463]$ and normal velocity $V_{n}^{*}=23.6 \mathrm{~km} / \mathrm{s}$. Since the normal magnetic field gradient is underestimated by $\sim 10 \%$, the translation velocity $U$ is overestimated. It is varying in time from the minimum 

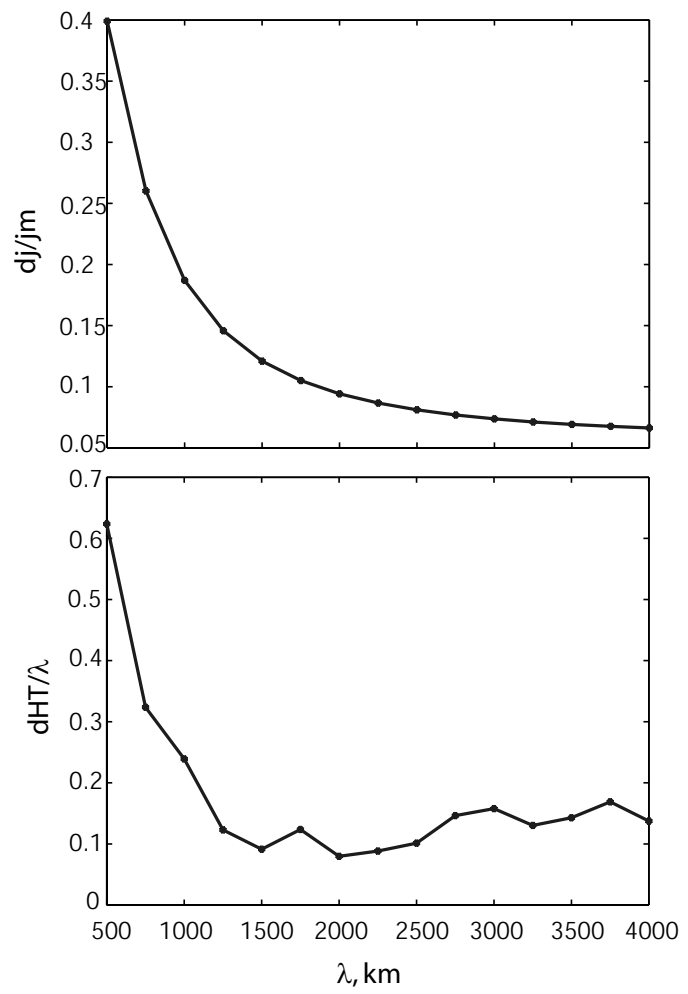

Fig. A3. Relative errors of current density (upper panel) and the current sheet half-thickness (bottom panel) estimates versus the model sheet half-thickness.

value of $28.5 \mathrm{~km} / \mathrm{s}$ (at the maximum of $\nabla_{n} \boldsymbol{B} \mathbf{1}$ ) to the maximum of $30.0 \mathrm{~km} / \mathrm{s}$ (at $\nabla_{n} \boldsymbol{B} \mathbf{1}$ minimum, calculations stopped when $\left.\nabla_{n} \boldsymbol{B}<0.5 \mathrm{nT} / 1000 \mathrm{~km}\right)$. The mean value of the effective translation velocity is $29.5 \mathrm{~km} / \mathrm{s}$. The effective width (or flapping amplitude) of the current neutral sheet $\left(S=\int U d t\right)$ is $9143 \mathrm{~km}$, which is $2100 \mathrm{~km}$ larger than the actual width $V_{n} \tau=7041 \mathrm{~km}$.

Figure A2 shows the mean values of the normalized divergence $|\nabla \cdot \mathbf{B}| /|\nabla \times \mathbf{B}|$ for the given set of the current sheet normal and half-thicknesses. The mean normalized divergence decreases with an increasing of $\lambda$ from 0.45 at $\lambda=500$ to 0.28 at $\lambda=2000$ and then stays near this level. Thus, for the structures with scales exceeding the maximum inter-spacecraft separation the divergence can hardly be a good measure of current density estimation error.

Summarizing many simulation runs Fig. A3 shows the relative error of the current density $d j / j_{m}=\left(\max \left(j_{m}\right)-\max \left(j_{r}\right)\right) / \max j_{m} \quad$ (upper panel) and the relative error of the half-thickness $d H T / \lambda$ (bottom panel) estimations as functions of model current sheet scale $\lambda$. In the range of $1500-3000 \mathrm{~km}$ (most frequent current sheet scales according to statistical analysis of Sect. 5.4) the relative error of current density estimates varies around $10 \%$ and the half-thickness overestimation is between $10 \%-15 \%$. The effective width $S$ is overestimated, its relative error changed from $70 \%$ at $\lambda=1000 \mathrm{~km}$ to $25 \%$ at $\lambda=4000 \mathrm{~km}$ (not shown).
Acknowledgements. We wish to thank H.-U. Eichelberger, G. Laky, L. Kistler, E. Georgescu and E. Penou for help with data and software, C. Cully, M. Fujimoto, L. Zelenyi, R. Treumann, M. Sitnov and $\mathrm{H}$. Malova for fruitful discussion. ACE spacecraft data are provided by N. Ness (Bartol Research Institute) and available on CDAWeb. This work is supported by INTAS 03-51-3738 grant, by RFBR N 03-02-17533 and N 03-05-20012, by WTZA AustriaRussia N I.1/04 grants, and the Intergeophysics Program. The work by MV was financially supported by the German Bundesministerium für Bildung und Forschung and the Zentrum für Luft- und Raumfahrt under contracts 50 OC 0104.

Topical Editor T. Pulkkinen thanks C. Mouikis and another referee for their help in evaluating this paper.

\section{References}

Asano, Y., Nakamura, R., Baumjohann, W., Runov, A., Vörös, Z., Volwerk, M., Zhang, T. L., Balogh, A., Klecker, B., and Rème, H.: How typical are atypical current sheets?, Geophys. Res. Lett., 32(L03 108), doi:10.1029/2004GL021 834, 2005.

Balogh, A., Carr, C., Acuña, M., Dunlop, M., Beek, T., Brown, P., Fornacon, K.-H., Georgescu, E., Glassmeier, K.-H., Harris, J., Musmann, G., Oddy, T., and Schwingenschuh, K.: The Cluster magnetic field investigation: Overview of inflight perfomance and initial results, Ann. Geophys., 19, 1207-1217, 2001.

Baumjohann, W. and Nakamura, R.: What is Cluster telling us about magnetotail dynamics, Adv. Space. Res., 99, in press, 2005.

Baumjohann, W., Paschmann, G., Scopke, N., Cattell, C., and Carlson, C.: Average ion moments in the plasma sheet boundary layer, J. Geophys. Res., 93, 11 507-11 520, 1988.

Baumjohann, W., Paschmann, G., Scopke, N., and Cattell, C.: Average plasma properties in the central plasma sheet, J. Geophys. Res., 94, 6597-6606, 1989.

Büchner, J. and Zelenyi, L.: Regular and chaotic charged particle motion in magnetotaillike field reversals, 1, Basic theory of trapped motion, J. Geophys. Res., 94, 11 821-11 842, 1989.

Chanteur, G.: Spatial interpolation for four spacecraft: Theory, in: Analysis Methods for Multi-Spacecraft Data, (Eds.) G. Paschmann and P. Daly, 349-369, ESA, Noordwijk, 1998.

Chanteur, G. and Harvey, C.: Spatial interpolation for four spacecraft: Application to magnetic gradients, in: Analysis Methods for Multi-Spacecraft Data, (Eds.) G. Paschmann and P. Daly, 349-369, ESA, Noordwijk, 1998.

Dunlop, M., Balogh, A., Glassmeier, K., and Robert, P.: Four-point Cluster application of magnetic field analysis tool: The Curlometer, J. Geophys. Res., 107, 1384, doi:10.1029/2001JA005 088, 2002.

Golovchanskaya, I. and Maltsev, Y.: On the identification of plasma sheet flapping waves observed by Cluster, Geophys. Res. Lett, 32(L02 102), doi:10.1029/2004GL021 552, 2004.

Harvey, C.: Spatial gradients and volumetric tensor, in: Analysis Methods for Multi-Spacecraft Data, (Eds.) G. Paschmann and P. Daly, 307-322, ESA, Noordwijk, 1998.

Hori, T., Maezawa, K., Saito, Y., and Mukai, T.: Average profile of ion flow and convection electric field in the near-Earth plasma sheet, Geophys. Res. Lett., 27, 1623-1626, 2000.

Karimabadi, H., Pritchett, P., Daughton, W., and Krauss-Varban, D.: Ion-ion kink instability in the magnetotail: 2 Threedimensional full particle and hybrid simulations and com- 
parison with observations, J. Geophys. Res., 108, 1401, doi:10.1029/2003JA010 109, 2003.

Kaufmann, R., Ball, B., Paterson, W., and Frank, L.: Plasma sheet thickness and electric currents, J. Geophys. Res., 106, 61796193, 2001.

Kistler, L., Mouikis, C., Möbius, E., Klecker, B., Sauvaud, J., Rème, H., Korth, A., Marocci, M., Lundin, R., Parks, G., and Balogh, A.: The contribution of non-adiabatic ions to the crosstail current and $\mathrm{O}^{+}$dominated thin plasma sheet, J. Geophys. Res., 110, in press, 2005.

Lee, L., Wang, S., Wei, C., and Tsurutani, B.: Streaming sausage, kink and tearing instabilities in a current sheet with application to the Earth's magnetotail, J. Geophys. Res., 93, 7354-7365, 1988.

Louarn, P., Fruit, G., Budnik, E., Sauvaud, J., Jacquey, C., Quéau, D., Rème, H., Lucek, E., Balogh, A., et al.: On the propagation of low frequency fluctuations in the plasmasheet: 1. CLUSTER observations and magnetohydrodynamic analysis, J. Geophys. Res., 109, A03 216, 10.1029/2003JA010 228, 2004.

Lui, A., Meng, C.-I., and Akasofu, S.-I.: Wavy nature of the magnetotail neutral sheet, Geophys. Res. Lett., 5, 279-282, 1978.

Nagai, T., Fujimoto, M., Saito, Y., Machida, S., Terasawa, T., Nakamura, R., Yamamoto, T., Mukai, T., Nishida, A., and Kokubun, S.: Structure and dynamics of magnetic reconnection for substorm onsets with Geotail observations, J. Geophys. Res., 103, 4419-4440, 1998.

Nakagawa, T. and Nishida, A.: Southward magnetic field in the neutral sheet produced by wavy motions propagating in the dawndusk direction, Geophys. Res. Lett., 16, 1265-1268, 1989.

Nakamura, R., Baumjohann, W., Runov, A., Volwerk, M., Zhang, T., Klecker, B., Bogdanova, Y., Roux, A., Balogh, A., Rème, H., Sauvaud, J., and Frey, H.: Fast flow during current sheet thinning, Geophys. Res. Lett., 29, 2140, doi:10.1029/2002GL016 200, 2002.

Petrukovich, A., Baumjohann, W., Nakamura, R., Balogh, A., Mukai, T., Glassmeier, K.-H., Rème, H., and Klecker, B.: Plasma sheet structure during strongly northward IMF, J. Geophys. Res., 108, 1258, doi:10.1029/2002JA009738, 2003.

Petrukovich, A., Baumjohann, W., Nakamura, R., Runov, A., and Balogh, A.: Cluster vision of the magnetotail current sheet on a macro-scale, J. Geophys. Res., 110, in press, 2005.

Rème, H., Aostin, C., Bosqued, J., Danduras, I., Lavraud, B., Sauvaud, J., Barthe, A., Bouyssou, J., Camus, T., Coeur-Joly, O., et al.: First multispacecraft ion measurements in and near the Earth's magnetosphere with the identical Cluster ion spectrometry (CIS) experiment, Ann. Geophys, 19, 1303-1354, 2001.

Ricci, P., Lapenta, G., and Brackbill, J.: Structure of the magnetotail current: Kinetic simulation and comparison with satellite observations, Geophys. Res. Lett., 31(L06 801), doi:10.1029/2002GL016 136, 2004.

Robert, P., Dunlop, M., Roux, A., and Chanteur, G.: Accuracy of Current Density Determination, in: Analysis Methods for MultiSpacecraft Data, (Eds.) G. Paschmann and P. Daly, 395-418, ESA, Noordwijk, 1998a.

Robert, P., Harvey, C., Dunlop, M., Daly, P., and Glassmeier, K.H.: Tetrahedron Geometric Factors, in: Analysis Methods for Multi-Spacecraft Data, (Eds.) G. Paschmann and P. Daly, 323348, ESA, Noordwijk, 1998b.
Runov, A., Nakamura, R., Baumjohann, W., Treumann, R., Zhang, T., Volwerk, M., Vörös, Z., Balogh, A., Glassmeier, K.-H., Klecker, B., Rème, H., and Kistler, L.: Current sheet structure near magnetic X-line observed by Cluster, Geophys. Res. Lett., 30, 1579, doi:10.1029/2002GL016730, 2003a.

Runov, A., Nakamura, R., Baumjohann, W., Zhang, T., Volwerk, M., Eichelberger, H.-U., and Balogh, A.: Cluster observation of a bifurcated current sheet, Geophys. Res. Lett., 30, 1036, doi:10.1029/2002GL016 136, 2003b.

Sanny, J., McPherron, R., Russel, C., Baker, D., Pulkkinen, T., and Nishida, A.: Growth-phase thinning of the near-Earth current sheet during CDAW 6 substorm, J. Geophys. Res., 99, 58055816, 1994.

Sergeev, V., Mitchell, D., Russell, C., and Williams, D.: Structure of the tail plasma/current sheet at $\sim 11 R_{E}$ and its changes in the course of a substorm, J. Geophys. Res, 98, 17 345-17 365, 1993.

Sergeev, V., Angelopulous, V., Carlson, C., and Sutcliffe, P.: Current sheet measurements within a flapping plasma sheet, J. Geophys. Res, 103, 9177-9188, 1998.

Sergeev, V., Runov, A., Baumjohann, W., Nakamura, R., Zhang, T., Volwerk, M., Balogh, A., Rème, H., Sauvaud, J., Andr, M., and Klecker, B.: Current sheet flapping motion and structure observed by Cluster, Geophys. Res. Lett., 30, 1327, doi:10.1029/2002GL016 500, 2003.

Sergeev, V., Runov, A., Baumjohann, W., Nakamura, R., Zhang, T., Balogh, A., Louarn, P., Sauvaud, J., and Rème, H.: Orientation and propagation of current sheet oscillations, Geophys. Res. Lett., 31(L05 807), doi:10.1029/2003GL019346, 2004.

Shen, C., Li, X., Dunlop, M., Liu, Z., Balogh, A., Baker, D., Hapgood, M., and Wang, X.: Analysis on the geometrical structure of magnetic field in the current sheet based on Cluster measurements, J. Geophys. Res., 108, 1168, doi:10.1029/2002JA009 612, 2003.

Sitnov, M., Swisdak, M., Drake, J., Guzdar, P., and Rogers, B.: A model of the bifurcated current sheet: 2. Flapping motion, Geophys. Res. Lett., 31(L09 805), doi:10.1029/2004GL019473, 2004.

Sonnerup, B. and Schneible, M.: Minimum and maximum variance analysis, in: Analysis Methods for Multi-Spacecraft Data, (Eds.) G. Paschmann and P. Daly, 185-220, ESA, Noordwijk, 1998.

Speiser, T. and Ness, N.: The neutral sheet in the geomagnetic tail: Its motion, equivalent currents, and field line reconnection through it, J. Geophys. Res., 72, 131-141, 1967.

Volwerk, M., Glassmeier, K.-H., Runov, A., Nakamura, R., Baumjohann, W., Klecker, B., Richter, I., Balogh, A., Rème, H., and Yumoto, K.: Flow burst induced large-scale plasma sheet oscillation, J. Geophys. Res., 109(A11 208), doi:10.1029/2004JA010 533, 2004.

Zhang, T., Baumjohann, W., Nakamura, R., Balogh, A., and Glassmeier, K.-H.: A wavy twisted neutral sheet observed by Cluster, Geophys. Res. Lett., 29, 1899, doi:10.1029/2002GL015 544, 2002.

Zhang, T., Baumjohann, W., Nakamura, R., Runov, A., Volwerk, M., Asano, Y., Vörös, Z., Eichelberger, H.-U., Sergeev, V., Shi, J., and Balogh, A.: A statistical survey of the neutral sheet, Adv. Space Res., 99, in press, 2005. 